
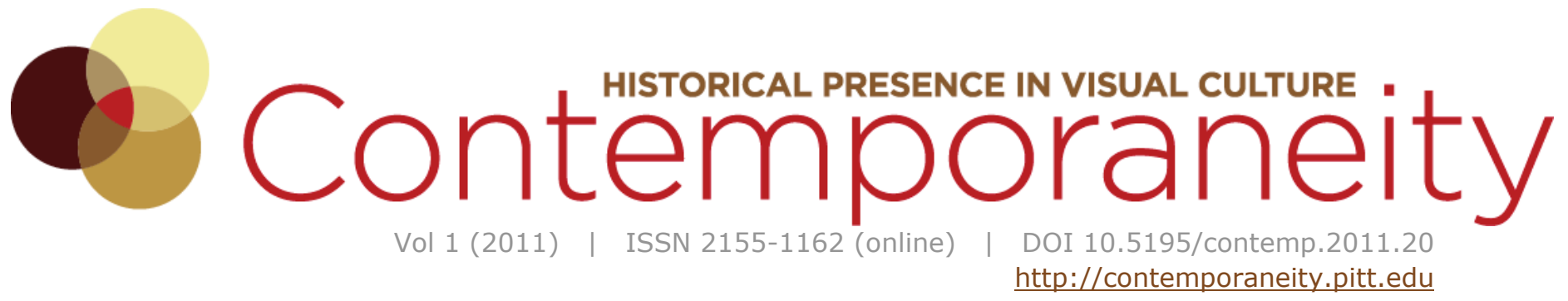

\title{
Waiting for Art The Experience of Real Time in Sculpture
}

\author{
Elizabeth Buhe
}

\begin{abstract}
Why and how does some contemporary art make us wait, and why does the beholder choose to stay? This study seeks to answer this question by exploring what happens to the viewer while waiting in front of a "time sculpture," a term coined here to mean a three-dimensional artwork that is dynamic over a set period of time. Through an analysis of select works by artists Anish Kapoor, Amelia Whitelaw, Michael Sailstorfer, and Roman Signer, the article posits that while in front of these time sculptures, the viewer experiences an anxiety of waiting and temporal confusion that glues him to the spot. Ultimately, by drawing upon Henri Bergson's concept of duration, the essay suggests that the viewership of time sculpture allows for a heightened state of perception.
\end{abstract}

\section{About the Author}

Elizabeth Buhe received her MA from The Courtauld Institute of Art in 2010 and has spent the last year in the Department of Sculpture and Decorative Arts at the J. Paul Getty Museum. 


\section{Waiting for Art}

\section{The Experience of Real Time in Sculpture}

Spending time waiting does not arrest or accelerate perception, but rather heightens it. In everyday life, actuality is forever escaping our grasp - once we perceive something it is already past - already an artifact, a history. The same is not true in the museum where, confronted by static objects, we are the ones with the agency to move. And we do move, until something captivates our gaze, entangles us. We choose to wait. What happens when these objects grab a hold of our attention and keep us there - looking, waiting? These works, which unfold in front of the viewer's eyes, pull the viewer into the object's temporal realm; this is a different conception of time.

In the museum, not many works actually make us wait for something to be revealed, using time as a device that affects us, that pervades our physical and mental space and grabs hold of our glance and our attention. As a conscious and deliberate means to force the viewer to experience the presentness of real time, contemporary artists have used their works to visualize time by allowing and even demanding the viewer to see and acutely feel the passage of time as a work moves before their eyes while they wait. The artist intentionally mediates the construction of time and how the viewer will experience it. Waiting for the work of art produces a temporal disturbance that takes us out of "human time" and puts us into the "object's time." As viewers, the moment in which we realize the collision of these two kinds of time causes a profound sense of anxiety. This is an anxiety caused by temporal uncertainty: the beholder's innate curiosity to understand the world prompts him to cede the agency of human time, to stay and reconcile the unknown durations of both the work and of his stay in front of it. The viewer is placed in an unsettling position by the "staging of an object as a temporal unfolding," a type of work which, as art historian Pamela Lee states, "violates a reading of the work of art as static, as ontologically secure, and as either genre or medium specific." ${ }^{1}$ She explains that it disrupts both how we view the work and how we conceive of its relationship to us in the museum space. Here the artist withholds something by disallowing the work from revealing itself in its entirety at first glance. It is precisely these works that I wish to consider: sculptures that unfold in real time in the gallery space, which I call "time sculptures." ${ }^{2}$ Though scattered within the oeuvres of many artists who have highly diverse practices and backgrounds, the similarity among these diverse works is the element of waiting. At time sculpture's core is the viewer's experience, and bringing into focus this unifying characteristic allows for a new line of inquiry. As an artwork which is purposefully designed to undergo changes over a set period of time, time sculpture most importantly rests upon the viewer's specific experience. By the very existence of its duration, time sculpture takes into account the viewer's presence by the waiting it presupposes. Time sculpture constructs the parameters through which the viewer must wait, through which the viewer sees and feels the presentness of real time on the object's terms.

\footnotetext{
1 Pamela Lee, Chronophobia: On Time in the Art of the 1960s (Cambridge, MA: MIT Press, 2004 ), 51. Lee's book examines art of the 1960s in the context of postwar culture and the Information Age. The author argues that art from this decade reveals a fundamental anxiety or uneasiness about time.

2 Though "time sculpture" as a term has been intermittently used by artists and critics to discuss artworks which engage questions of temporality - as in the case of Swiss artist Roman Signer, discussed later in this paper - there is no regularly accepted definition of this terminology, nor is there extensive theory on this specific issue. My extension of the use of the term encompasses several different art practices, delimited by works which require the human element of waiting.
} 
With this definition in mind, I will argue that the anxiety-inducing experience of "waiting for art" heightens our perception so that we are more fully engaged in the act of viewership. ${ }^{3}$ It is the anticipation and thus anxiety that time sculpture arouses in us, the confusion of the temporal parameters through which we experience it - human time or object time - that leads to a heightened state of awareness, and arguably, even impels us to stay longer. The longer we stay, the more anxiety mounts, raising the stakes so that we demand the moment of catharsis even more intensely. In this way, anxiety and waiting are united in an inextricable bond, and must be relieved simultaneously. Further, we should note that this time-based anxiety is very different from the unease aroused by the work's content and our subsequent associations. Although both contribute to heightening attentiveness, it is the temporal anxiety we feel that glues us to the spot, heightens our perception, and makes time sculpture worthy of further inquiry. I have chosen to focus on time sculpture as opposed to other modes of art that take place in real time such as performance art, new media, and film because the unexpected perceptual experience of an inanimate object interfering with our sense of time is a unique, jarring, anxiety-producing encounter. ${ }^{4}$

Necessarily, my observations rest on limitations. Understanding art by grouping it according to overall style or region has become increasingly insufficient given the speed, volume, and level of inter-connectedness with which it is being produced today. The very fact that this trend is manifest in the work of a diverse group of artists suggests its wide-ranging resonance and its importance for further inquiry. Though the oeuvres of each of the artists considered here are different in many ways, they all involve themes of anxiety, process, time, and its effects. What brings these works together is their relationship to the passage of time in the gallery. ${ }^{5}$ The works themselves are not expressly about waiting, but the act of waiting is central to the viewer's perception of them. ${ }^{6}$

3 Jonathan Crary's seminal work Suspensions of Perception offers a thorough study of the relationship between perception and art in terms of societal change. It posits that in the late-nineteenth century, modes of perception changed in accord with a growing disorder of the social experience in a capitalist world, affecting how people saw the work of art, a shift reflected in radical changes in the artist's method through the development of novel forms of visual depiction. See Jonathan Crary, Suspensions of Perception: Attention, Spectacle, and Modern Culture (Cambridge, MA: MIT Press, 2001).

${ }^{4}$ Nicolas Bourriaud's theory of relational aesthetics could offer a further lens through which to analyze time sculpture; however, for the purpose of this article, the individual encounter with the work of art is privileged over the collective experience, a choice necessitated by the importance of the individual mind to Bergson's theories of perception as later discussed.

${ }^{5}$ The limited scope of this article makes it impossible to discuss the many works relevant to an investigation of time sculpture. I have restricted the number of works analyzed to those I have seen in person, given that the experience of seeing (and waiting for) a work is so intrinsic to time sculpture. Yet even within these parameters, there is an abundance of time sculpture (for example, see works by Rebecca Horn or Arcangelo Sassolino), which merit attention and which could enrich a further investigation.

${ }^{6}$ A number of recent exhibitions have dealt explicitly with the question of time in art and society, suggesting a heightened interest in the topic. "As Soon As Possible: Acceleration in Contemporary Society" at the Palazzo Strozzi in Florence in summer 2010 showcased artists whose work addressed the show's theme of a heightened sensitivity to time. See Centre for Contemporary Culture Strozzina, As Soon As Possible: Acceleration in Contemporary Society, exhibition catalog (Florence: Centre for Contemporary Culture Strozzina, 2010). The 2008 Whitney Biennial was concerned with a "temporal tenuousness - the sense many artists feel of being in transition" and with a re-conception of time, which curator Shamim Momin saw manifest in the works as either an investigation of time and process through sculpture as a spatialization of time, or a non-linear trend through seriality in a system-based versus medium-specific production. See Shamim M. Momin, "Time Change," in Whitney Biennial 2008, ed. Henriette Huldisch and Shamim M. Momin, exhibition catalog (New York: Whitney Museum of American Art, 2008), 51-78. Further, The Courtauld Institute of Art's East Wing VIII exhibition "On Time" explored notions of temporality, as well as constructed, deconstructed, modified, and manipulated time. It showcased The Fall, a work by Amelia Whitelaw discussed in detail later in this article. See Eleanor Clayton, et al., eds., 
The first section of this article defines time sculpture first by way of Michael Fried's criticism of minimalist sculpture in the 1960 s, taking his analysis of this work as the arthistorical beginning of the relationship between sculpture, anxiety, and the viewer. The second section explores this anxiety as it relates to the time sculptures of four contemporary artists and the various durations present in each, as well as to the oeuvre of each of those artists more broadly. Finally, section three details the effect of this anxiety on our perception, where the interval of the viewer's mental activity while in front of the work is pivotal to the result of heightened awareness.

\section{Time Sculpture: Some History and Limitations}

Sculpture's relationship to a temporal duration was famously articulated by Michael Fried in his essay "Art and Objecthood" from 1967, which, according to Pamela Lee, "inscribes a marked anxiety about time. "7 Fried's notion that the viewer's presence had become essential to the understanding of a sculptural work provides the foundation for our analysis of a sculpture-catalyzed anxiety. The ideas he developed have implications for a contemporary reading of anxiety and for temporal duration in art today, though in a decidedly different way. In the 1960s, minimalist artists were reducing sculpture to its most fundamental forms, creating work which could not be read as illusionistic and consisted only of its most necessary elements. Fried's discomfort about these developments, which he thought denied the viewer a proper aesthetic experience, led him to argue in "Art and Objecthood" that minimalism (or "literalism," as he called it) betrayed the accomplishments of Modernism because the meaning of the work was not wholly manifest, as it was contingent upon the viewer's presence:

Literalist sensibility... is concerned with the actual circumstances in which the beholder encounters [it]... Whereas in previous art 'what is to be had from the work is located strictly within [it],' the experience of literalist art is of an object in a situation - one which, virtually by definition, includes the beholder. ${ }^{8}$

This contingency on the external element - the viewer's presence, which was crucial to the work's meaning - prompted Fried to assert that minimalist sculpture was approaching what he called "objecthood." This was a mere thing-like status or a non-art condition. According to Fried, literalist sculpture lacked what he called "presentness."

For Fried, this objecthood derived from two interrelated conditions. First, he saw minimalist sculpture as theatrical because its meaning was not intrinsic, requiring the individual experience of the viewer. The work engulfs the viewer, challenging him to confront it "within a situation which he experiences as his," which "means that there is an important sense in which the work in question exists for him alone, even if he is not actually alone with

On Time: East Wing Collection VIII, exhibition catalog (London: The Courtauld Institute of Art, 2008). Finally, "Disarming Matter" at the Dunkers Kulturhus investigated the self-erasure, withdrawal, or negation of matter in both the physical and mental sense through art. See AnnCatrin Gummesson, et al., eds., Disarming Matter, exhibition catalog (Helsingborg: Dunkers Kulturhus, 2008).

7 The author goes on to delineate the kind of time that concerned Fried: "Time in the work of art; time in the experience of minimalism as quotidian; time experienced as the endless, 'on and on' of a new kind of art making. Time as the foundation of what Fried called theatricality: the staging of minimalist sculpture as contiguous with the actual conditions of the beholder's surroundings." Lee, Chronophobia, 38. Note, however, that Fried did not employ the term "anxiety" in "Art and Objecthood," discussed in this section.

8 Michael Fried, "Art and Objecthood," Artforum 5 (June 1967), 15. 
the work at the time." ${ }^{\prime 9}$ Second, Fried saw this theatricality to have an endless duration, or to be dependent upon the potential for the beholder's experience in front of the work to never end. The former relies upon the latter because, as Fried states, it is "above all the endlessness, or objectlessness, of the approach or onrush or perspective" - in all, the beholder's experience - which replaces the object. ${ }^{10}$ In short, objecthood derives from the theatricality of the viewer's participation, which itself may be endless.

It is Fried's notion of endlessness which brings us to time sculpture. While the "theatricality" of time sculpture is manifest in the same way that Fried saw it (requiring the viewer's presence), the divergence lies in what he presumes to be its endless condition. While static sculpture creates experiences that can endure, time sculpture creates a temporal break that defines the duration(s) of the beholder's experience. When spending time in the gallery with a time sculpture we are not entirely free of temporal limitations, simply because we know we are waiting for something to happen. We wait for catharsis: a culmination of our period of waiting, a fulfillment of time sculpture's promise to the beholder, and a subsequent alleviation of our anxiety. In its way, while we wait time sculpture has us in its grasp, but is quite different from the experience defined by Fried in terms of "a presentment of endless, or indefinite, duration." 11 His argument has renewed relevance because time sculpture has a defined duration for the viewer: Fried's endlessness is no longer in play; hence, we need to re-evaluate how anxiety functions in the sculptural realm. Theatrical in the experience it presupposes, time sculpture drives at an anxiety much different from Fried's discomfort over the inexhaustibility of literalist work. Time sculpture defeats this anxiety, but in its "endness," it creates an anxiety not of the critic, but of the viewer.

This article explores how the duration of waiting for the work of art and the subsequent cathartic break affect the viewer's experience. There are no "right" or "wrong" ways for the beholder to determine the length of his stay in front of a work. Indeed, across different time sculptures there can be multiple durations with varying degrees of cathartic release. However, for all time sculpture, our primary anxiety as viewers is the realization that our own time is ruptured by these durations. It is the cognizance that these intervals exist explicitly - that a cathartic moment will occur, and that this will happen outside our control - which cements our anticipation as viewers of time sculpture.

In our lives, humans are always on the move; objects are not - or at least not seemingly of their own accord. We relate to other humans on our own terms, in our own time, in a way that we cannot relate to inanimate objects in our space. From these objects, we expect something different, a non-threatening presence, a sense of being "in the background." Yet time sculpture is in our space and in our way, so that this attitude toward "the object" becomes inadequate or impossible. We thus become anxious because of the temporal and spatial disruptions that compel us to relate to objects outside everyday terms. This anxiety arises from a realization of the collision of human time and object time, and only in time sculpture does it have the capacity to shift the viewer's state of awareness to one of such enhanced perception.

\footnotetext{
${ }^{9}$ Ibid., 21. Art historian Rosalind Krauss explained the beholder's role in this interplay in the following way: "By the mid 1960s, it was clear that theatricality and performance could produce an operational divide between the sculptural object and the preconceptions about knowledge that the viewer might have about both it and himself." Rosalind Krauss, Passages in Modern Sculpture (Cambridge, MA: MIT Press, 1981), 240.

10 Fried, "Art and Objecthood," 19.

11 Ibid., 22.
} 


\section{Anxiously Waiting: Views in the Gallery}

Anish Kapoor's Shooting into the Corner (2008-9) and Svayambh (2007) sit tightly in their galleries (Figs. 1-2). ${ }^{12}$ Each is surrounded by empty space and bright white walls, yet the space seems used up, not empty at all. Our first glance registers this as a desolate place: the history of destruction is everywhere. Judging by the spatters of red wax spread across the walls and the ceiling near Shooting into the Corner, the lumps of redness hanging on the gallery doorways, and the crimson covering smeared along the track on which Svayambh sits, it is clear that these works were not - or are not - entirely static. In this moment of hesitation, both beckon the beholder to come closer to investigate. The apparatus of each work becomes apparent: a sleek pneumatic cannon larger than the human body in the case of Shooting into the Corner and a sunken metal rail, covered by the red substance itself in the case of Svayambh. Replacing the gesture of the artist, this mechanization suggests a loss of subjectivity, a sense that the work has given itself over to a pre-determined set of rules. Yet the accumulation of material throughout the gallery suggests something else: that some force of nature is at work here, slowly shaping the formulation of material in space.

The cannon firing cartridges of scarlet wax into the corner suggests an additive process rather than a destructive one, unsettling and difficult to reconcile given the work's reference to the human body. Kapoor himself describes the process as "very violent and deeply phallic," contrasting it with the symbolic interpretation of the corner as "a fundamental beginning point for architecture, of creation - it is feminine." ${ }^{13}$ Given the deep redness and viscous residue of the works, the reference to the human body, violence, ejaculation, and menstruation is undeniable, further jarring the beholder into a state of unease. ${ }^{14}$ Confusion over this additive and destructive process begs the question: is the work finished? Rarely do we expect to come to an art museum to see the fabrication of a work in progress, a visual unfolding in real time, yet it seems that is exactly the circumstance in which the viewer finds himself. ${ }^{15}$ It is an uncomfortable, if seductive, situation. The slow-moving rectangle has already been formed at the top into the shape of the galleries' doorways; alongside, another twenty-pound lump of wax is projected, adding to the heap. But it is not with the effects themselves, but with "bringing about a heightened sensibility on the part of the viewer, who suddenly becomes aware of losing his safe distance from the object" that Kapoor's ultimate concern lies. ${ }^{16}$ As we wait, Kapoor throws us, like the works, into a transitional state. What are we waiting for?

\footnotetext{
12 These works are described as seen at the Royal Academy of Arts, London, in the exhibition "Anish Kapoor," September 26, 2009 - December 11, 2009.

13 Gabriel Ramin Schor, "In the End Was the Vaseline: On Anish Kapoor's Shooting 'Beyond the Pleasure Principle,'" in Anish Kapoor: Shooting into the Corner, ed. Peter Noever, exhibition catalog (Ostfildern: Hatje Cantz, 2009), 162.

14 Alternatively, it has been suggested that Svayambh alludes to the trains on which the Nazis deported people to concentration camps, particularly in light of Kapoor's partially Jewish heritage. Kapoor's initial idea was to name the work Paint Train. See Gilles A. Tiberghien, "Entretien," in Anish Kapoor: Svayambh, ed. Charlotte Lair de la Motte, exhibition catalog (Nantes: Musée des Beaux-Arts, 2007), 21.

15 Neither Svayambh nor Shooting into the Corner was conceived specifically for the Royal Academy exhibition, though this was the first occasion in which they were shown together. Svayambh had previously been exhibited at the Musée des Beaux-Arts de Nantes (2007) and the Haus der Kunst, Munich (2007-8). Shooting into the Corner is owned by MAK Museum for Applied Arts / Contemporary Art, Vienna, where it was first shown in 2009; it was also on view at the Guggenheim Museum Bilbao in summer 2010.

16 Camiel van Winkel, "On the Sublime in the Work of Anish Kapoor," in Anish Kapoor, exhibition catalog (London: Royal Academy of Arts, 2009), 168.
} 


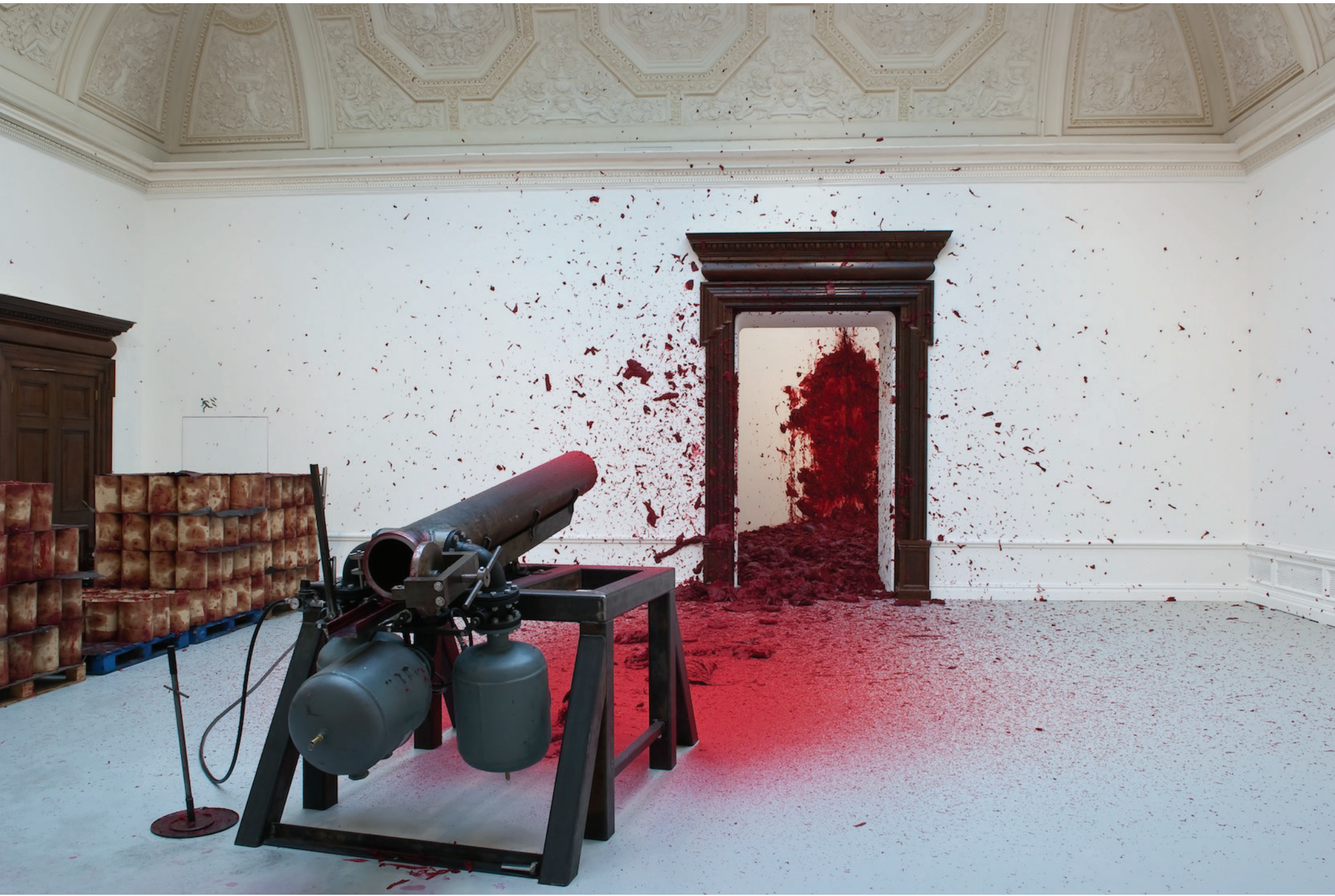

Figure 1

Anish Kapoor, Shooting into the Corner, (2008-9). Mixed media. Dimensions variable. Installation: Royal Academy of Arts, London, 2009. Photo: Dave Morgan.

Courtesy of the artist. 


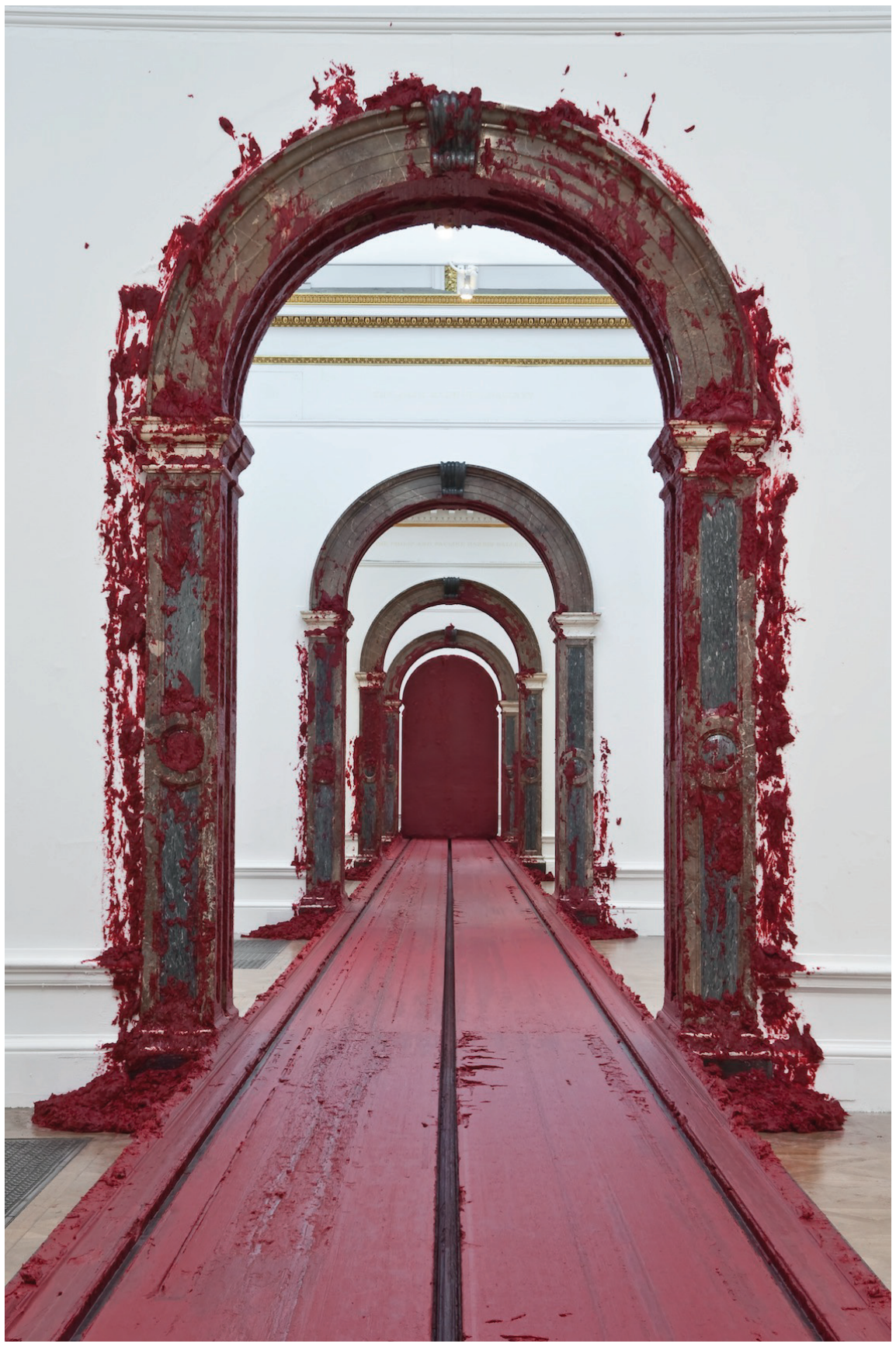

Figure 2

Anish Kapoor, Svayambh, (2007). Wax and oil-based paint. Dimensions variable. Installation: Royal Academy of Arts, London, 2009. Photo: Dave Morgan.

Courtesy of the artist and the Royal Academy of Arts. 
This uncomfortable anticipation translates into feeling a loss of control. Kapoor's works develop a distinct duration in which we realize we are anxiously waiting on the object's terms. We know Svayambh moves slowly through its galleries; the noise of an explosion heard muffled several galleries away tells us that Shooting into the Corner will detonate at regular intervals. But this does not quell our fears or satiate our curiosity: is recognizing the dynamism of these works enough? No. We wait. How does the work move? What happens when the cannon releases? When does this object come into being? The collective act of waiting creates a unique experience, a temporal anticipation that is central to the work. Indeed, though the gallery guide stated that "a cannon is fired at twenty-minute intervals," museum guards were instructed by the curators not to tell curious visitors, when asked, how frequently the cannon would fire. ${ }^{17}$ The beholder's loss of control, then, was very much intentional. ${ }^{18}$

As the exhibition's popularity grew, visitors had increasingly heard about these two wax works and the experience of waiting to see them in motion. ${ }^{19}$ The waiting wall of people became part of the exhibition, perhaps explaining why Kapoor alternatively described the show as both theatrical and mysterious, hoping that his work would "maintain its mystery and never reveal its plan...I want to try to make things that remain secret." ${ }^{20}$ Throughout his artistic practice, Kapoor has been interested in concealing the artist's presence. As he put it: "I have a fantasy about the auto-generated, self-made, somehow revealed object... I want to deny the hand. I want to get beyond gesture." ${ }^{21}$ Indeed, "svayambh" comes from the Sanskrit word svayam, meaning "in person, oneself, itself, of one's accord," and of it, Kapoor said, "The form, I insist, made itself," denying the viewer knowledge of authorship. ${ }^{22}$

By confusing our notion of how and by whom these works were made, Kapoor aims to resituate the viewer in relation to his works. He stated:

I am interested in sculpture that manipulates the viewer into a specific relation with both space and time. Time, on two levels: one narratively and cinematically as a matter of the passage through the work, and the other as a literal elongation of the moment....Space is as complex. The space contained in an object must be bigger than the object which contains it. My aim is to separate the object from its object-hood. ${ }^{23}$

In separating his self-proclaimed "object" from its "objecthood," Kapoor effectively claims his work as "art," directly referencing Fried. In desiring a "literal elongation of the moment," Kapoor acknowledges that his works do have an end, and thus come up against the

\footnotetext{
17 Royal Academy, Anish Kapoor, gallery guide, "Shooting into the Corner."

18 Adrian Locke, Exhibitions Curator at the Royal Academy of Arts, conversation with author, July 26, 2010, London. The cannon was manned by a team of cannoniers comprised of local theater students. Suited up in black, they were instructed to shoot the cannon at regular intervals and retreat to a chair in the corner after detonating the cannon, functioning as triggers for a repeated act.

19 The aspect of external promotion and spectacle is underscored by the fact that the Royal Academy had a camera streaming live action video of the cannon on its website for the duration of the show. The visitor numbers for "Anish Kapoor" were an all-time record for an exhibition of a living artist at the Royal Academy, at around 277,500 people. Locke, conversation with author, July 26, 2010.

20 Heidi Reitmaier, "Descent into Limbo," Tate International Arts and Culture 1 (September - October 2002), 92.

21 Homi Bhabha, "Homi Bhabha and Anish Kapoor in Conversation, 1st June 1993," in Anish Kapoor, ed. Nehama Guralnik, exhibition catalog (Tel Aviv: Tel Aviv Museum of Art, 1993), 61.

22 Sandhini Poddar, "Suspending Disbelief: Anish Kapoor's Mental Sculpture," in Anish Kapoor: Memory, exhibition catalog (New York: Guggenheim Museum Publications, 2008), 34.

23 Reitmaier, "Descent into Limbo," 92.
} 
"endlessness" (and subsequent "objecthood") Fried rejected. Rather, Kapoor's elongation of the moment corresponds to the duration of time in which the viewer waits for the work of art.

Similarly, Amelia Whitelaw's viscous, seeping dough sculpture unravels in real time, confronting the viewer both with its process and the residue of its journey through time and space. Suspended in its net encasement, The Fall (2008-9), a mass of fresh salt dough, hangs in a stairwell, slowly traversing its container (Figs. 3-4). ${ }^{24}$ Gravity coaxes the dough downward, and initially it retains its unity of form. With each passing moment, the mixture is sectioned by the square-patterned ropes of the netting into bulbous forms, detaching from the sagging mass in tresses like the tentacles of an octopus moving fluidly outward from its body. The first chunk falls downward, only to be caught by another disk of netting, to accumulate and fall again; four nets of decreasing diameter slow the dough's descent until it reaches the floor. Stasis. The stairwell acts as an attention tool, training the eye upward and back downward as more dough leaks toward the floor. ${ }^{25}$ No end is in sight.

At the same time that the dough persists downward, particles cling to the fibers of the rope, recalling the passing of movement, imploring not to be forgotten or swallowed up by pieces to come. It is a haunting of both the actual moment and the moments to follow, rendering visible different durations layered upon each other. As the dough continues to collapse, it slows, eventually becoming a sculpture of frozen action suspended delicately and vertically in space. Over the course of the exhibition, air hardens the dough so it eventually grows static, its loss of movement rendering it an object. ${ }^{26}$ For Whitelaw, this remainder is key: "The only testimony of our passing is collective memory...what is left at the end of the process, the residue, the elastic concept of time and memory." ${ }^{27}$ As we wait, the interval of our attention is variable, arguably heightening our level of engagement. Do we seek to witness the catch and release of one, two, three masses of dough? To see the first splat of dough on the floor? Or to see the dynamism of the work over the whole course of its showing? As Whitelaw put it:

The waiting and reward are a significant factor of these works. I have often found myself trapped watching the pieces until it reaches a slowed state of momentum.... Tentative to start, speeding up to a frenzy, finally exhausting to an eventual stop. ${ }^{28}$

Unlike the rhythmic nature of Kapoor's works, this elongation of time is undefined, the level of incident is less stark, and the parameters of the beholder's experience are more subjective. This is an understanding of the passage of time as physical or visible rather than conceptual, of natural rather than mechanical. Yet once again the beholder has no control:

\footnotetext{
24 The Fall was shown in the exhibition "On Time" at The Courtauld Institute of Art, January 26, 2008 July 26, 2009. Whitelaw's first suspended dough work was entitled As In Death, an iteration in which she "restricted the viewing of it until after the piece, in effect, had 'died.'" Hence, it denoted a marked difference from The Fall in which the beholder's presence was key. Whitelaw, e-mail message to author, August 28, 2010.

25 Of the function of the stairwell and the beholder's ability to change perspective by climbing or descending it, Whitelaw stated, "By making use of the entire height of the stairwell I gave the experiential responsibility over to the viewer." Amelia Whitelaw, e-mail message to author, August 29, 2010.

26 Jack Hartnell, curator of "On Time" at the Courtauld Institute of Art, conversation with author, July 13, 2010, London.

27 Susanna Bianchini, "Spotlight: Amelia Whitelaw," Cura Magazine 4 (April 2010), http://www.curamagazine.co m/en/?p=1033.

28 Whitelaw, e-mail message to author, August 29, 2010.
} 


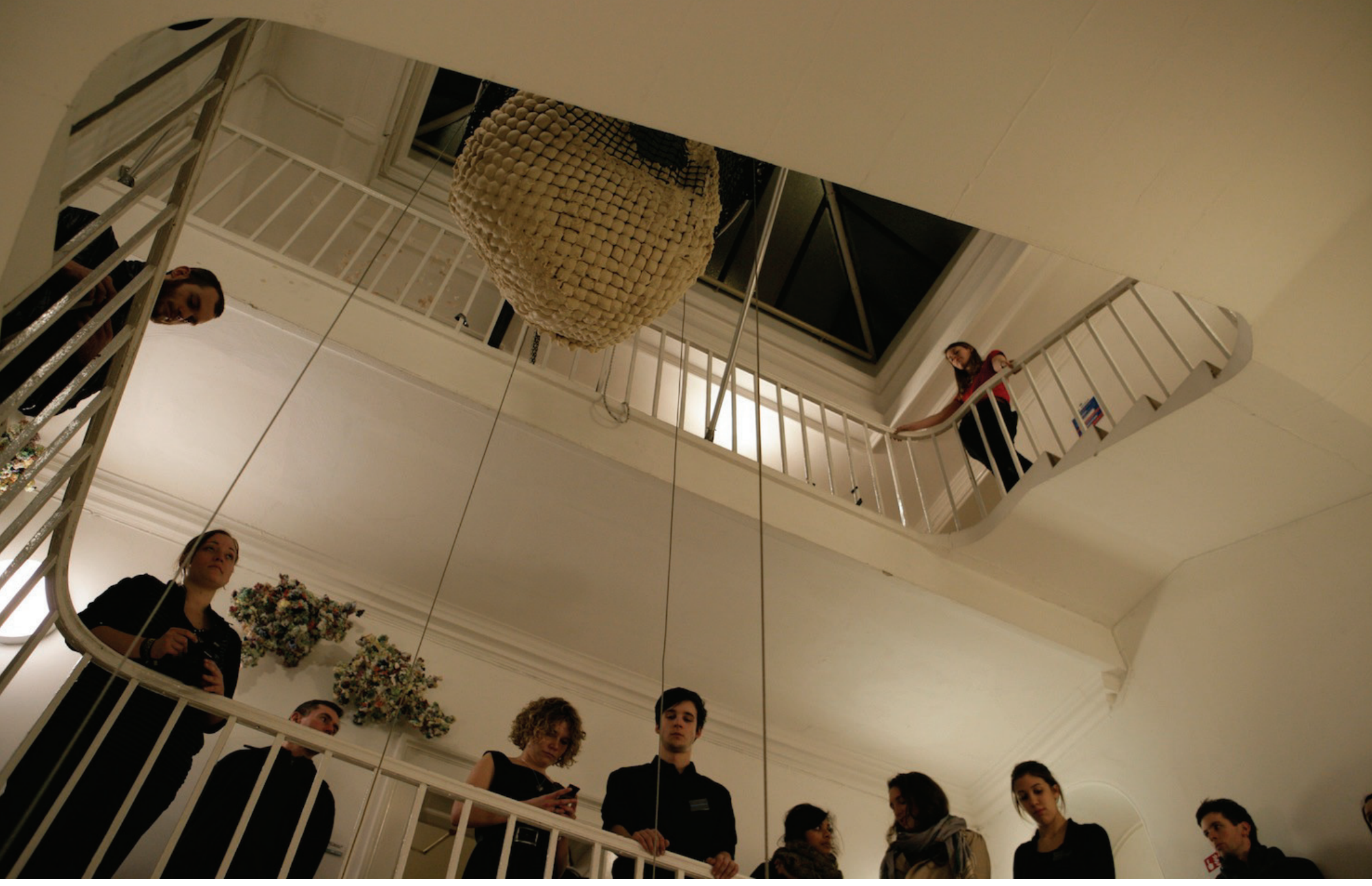

Figure 3

Amelia Whitelaw, The Fall, (2008-9). Mixed media. Dimensions variable. Installation: The Courtauld Institute of Art, 2008-9. Photo: Ross McNicol.

Courtesy of the artist and the Wallis Gallery. 


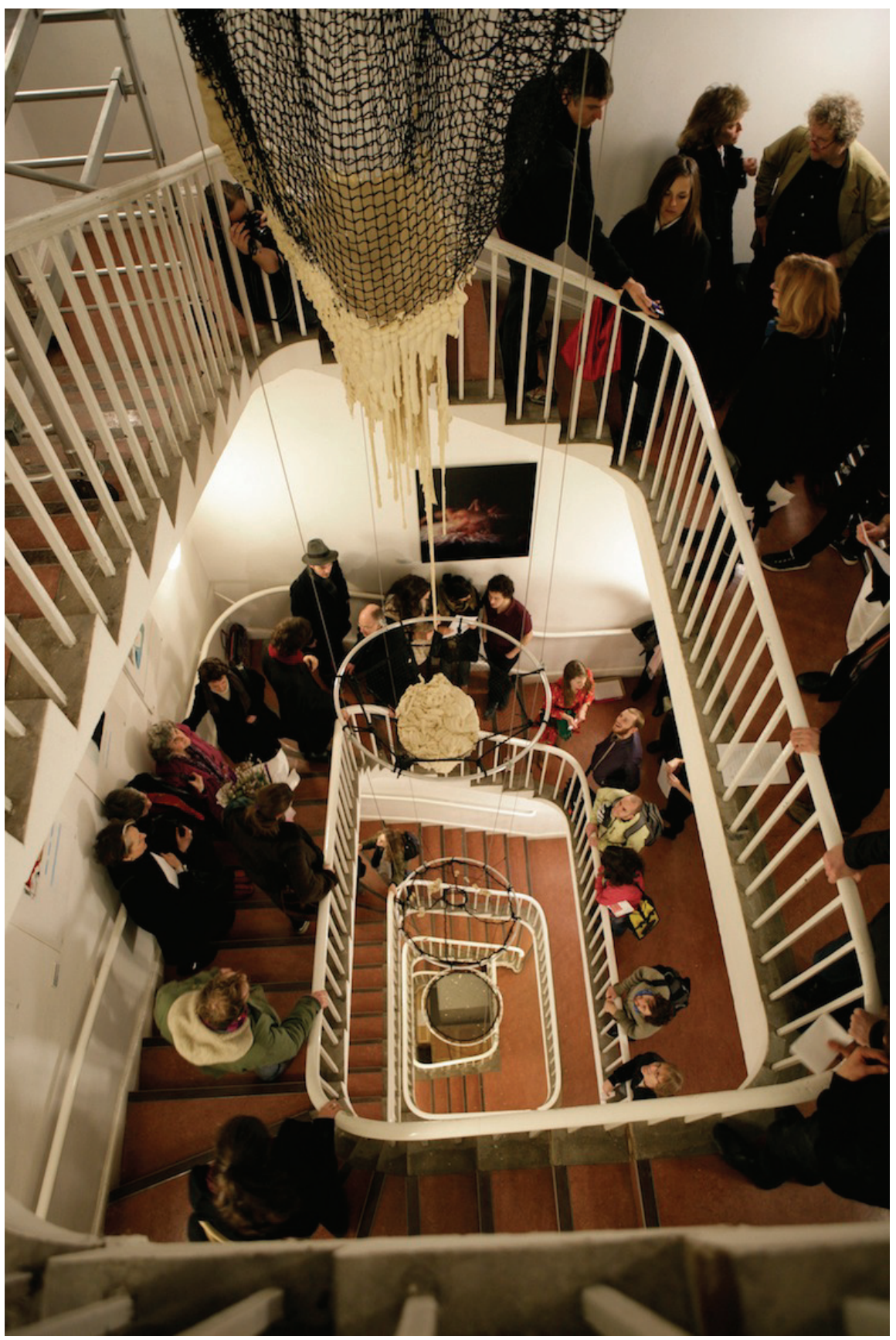

Figure 4

Amelia Whitelaw, The Fall, (2008-9). Mixed media. Dimensions variable. Installation: The Courtauld Institute of Art, 2008-9. Photo: Ross McNicol.

Courtesy of the artist and the Wallis Gallery. 
gravity and chance take over. Even the artist has surrendered agency to the accident of these natural forces. ${ }^{29}$

Like the morphing materiality and remains of Kapoor's work, The Fall enraptures the viewer by rupturing expectations of passivity in the gallery. Indeed, Whitelaw said: "I found that the dough installations impose an innate responsibility for the witness. The observer is lured into following the progression of a strand or clump of dough as though by watching one gives the form value." ${ }^{30}$ As a presence in our very space, it captures our attention, alluring us to stay, to watch and wait, to feel the vividness of time's measure.

The cyclical processes of creation, destruction, and regeneration are also central to the work of German artist Michael Sailstorfer. Spinning relentlessly, futilely, and infinitely to its own self-destruction, Zeit ist keine Autobahn (2005-) consists of a tire pressed against the gallery wall powered by an electric motor (Fig. 5). ${ }^{31}$ The putrid scent of burning rubber can be detected much before we can see or hear its source, heightening our senses and our anticipation. Splattered rubber particles cover the wall, slowly piling up in a mound below the work, telling of its continual struggle to move not only toward some undefined horizon, but also toward its own friction-caused disintegration. Tiny pieces of plaster from the gallery wall can be spotted amongst the sooty-black debris, suggesting that it is not solely the tire that is at risk of destruction.

The tire's exact rate of decay is unpredictable, determined by the energy the engine consistently supplies and the uneven pressure of the plaster. As with Whitelaw's dough sculpture, the level of incident is minimal, and the duration of the beholder's attention is less easily defined, for there is no cannon explosion to wait for here; instead, we wait for a discernable accumulation of rubbery dust below the wheel to render time visible. Situated waist-high on the wall, the work's absurdity becomes immediately apparent, defying our most basic understanding of a tire's functionality and the impossibility of seeing it up-close in motion. Our initial reading of the work as a tire like any other is quickly and repeatedly annulled by the blackened carnage below and the stench of exposed rubber, which bring to the fore the process-based questions of temporality, endlessness, mobility, and decay. Though moving, it goes nowhere, trapped in a state of perpetual immobility as intimidating as it is impotent. Yet it is exactly this kind of contradiction that puts us at unease. Sailstorfer turns quotidian objects into sculptures void of functional value, challenging the way we normally read them.

One contradiction in particular lies at the heart of Sailstorfer's artistic investigation: as he puts it, his current preoccupation is with "travelling and yet still settling down somehow, or feeling at home in the interim space." 32 This tension between home and travel, stability and flux is one we can all relate to, and is alarming for threatening to come so close to - or,

\footnotetext{
29 Set into motion by Jack Hartnell, the curator of the Courtauld exhibition "On Time," the 440-pound mass of dough was released only once. The artist had no part in this action: "I was there, strangely impassive, and I was waiting to see if everything would fall down or stay up..." said Whitelaw. See Bianchini, "Spotlight: Amelia Whitelaw."

30 Whitelaw, e-mail message to author, August 28, 2010.

31 Zeit ist keine Autobahn was conceived in 2005 for the Yokohama Triennale and has since been shown in various other venues, including Frankfurt, Berlin, Minneapolis, and Florence. Each time, the name of the city in which the exhibition was located was appended to the title of the work. The specific installation referred to here is Zeit ist keine Autobahn, Minneapolis, shown at the Walker Art Center's exhibition "The Quick and the Dead," April 25, 2009 - September 27, 2009. The English translation of the work's title is Time is No Highway.

32 Helmut Friedel, "Michael Sailstorfer and Helmut Friedel," in Michael Sailstorfer, ed. Giovanni Iovane (Paris: Dena Foundation for Contemporary Art, 2005), unpaginated.
} 


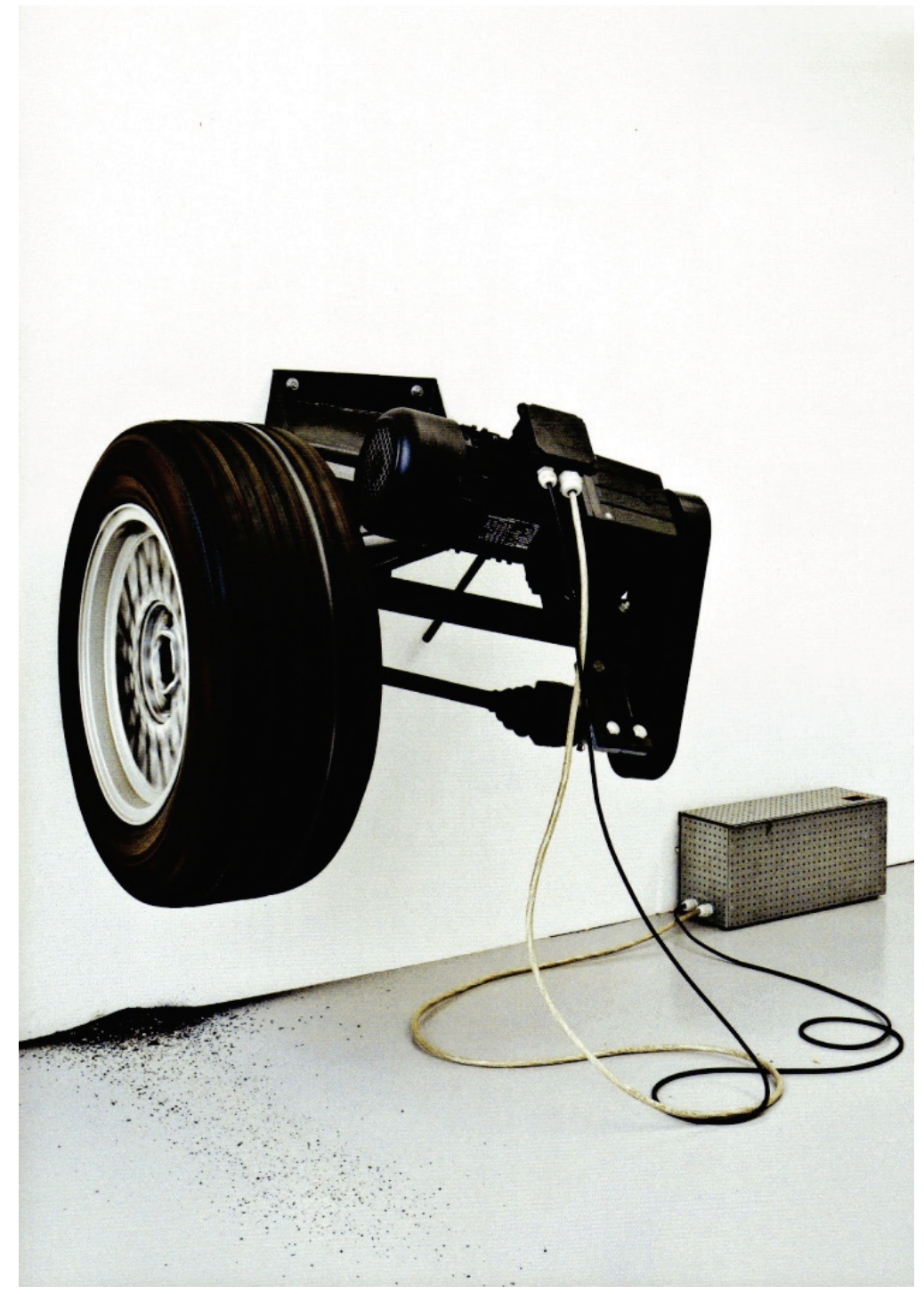

Figure 5

Michael Sailstorfer, Zeit is keine Autobahn - Frankfurt, (2008). Tire, iron, electronic engine, electric current, wall. Dimensions: $80 \times 95 \times 65 \mathrm{~cm}$ (31 1/2 x $371 / 2 \times 251 / 2$ in). Photo: Norbert Miguletz $\odot V G$ Bild-Kunst, Bonn.

Courtesy of Johann König, Berlin. 
alternatively, to suspend - our retreat to that which is our closest, most private, and most protected space. Like time, space is something we understand based only on experiential knowledge - indeed Sailstorfer is fascinated by space because "we cannot really grasp or explain how it all relates" - and the confrontation of this uncertainty is disconcerting. ${ }^{33}$ To understand the space between, or from, point A to point B, we must understand what or where those two points are. Yet Sailstorfer's work addresses this very "interim space," this interval of transience, non-identity, and turbulence. The non-travel of the tire reveals the catastrophe of its condition. Waiting restlessly, the visitor feels the anxiety of this active paralysis. The work's title, Zeit ist keine Autobahn (or Time is No Highway), suggests the consistency of time: though the tire tries hopelessly to accelerate, time takes time, its speed invariable, based necessarily only upon our own subjective exposure. The tire's process of destruction and replacement both affirms the consistency of time's measure and the suspicion that it will self-destruct only in its own time - its object time.

The experience of waiting is also exemplified by the work of Swiss artist Roman Signer, a self-described artist of time sculpture. ${ }^{34}$ Renowned for the literal explosiveness of his works, the state of transition, the transformation of matter, and the traceable duration of time within an explosion comprise, for Signer, the essential components of sculpture. He is "fascinated by changes of state. A sudden switch in the case of a slow movement - for example a fuse is burning slowly, and then suddenly the explosion comes. That is a sculpture, a time sculpture, a combination of very slow and very fast." ${ }^{35}$ And yet, in his work, this discernable moment of flux for which we wait need not necessarily be an explosion. The passage from slow to fast and the tension between stasis and movement are the central tenets of his work Rad (Wheel) (1996/2008) (Fig. 6). A bicycle wheel standing upright, its lower rim frozen into an oblong block of ice, sits quietly in the center of the gallery, perched upon a low pedestal with a raised perimeter to prevent the water from spreading across the floor. ${ }^{36}$ Like the objects in Sailstorfer's work, Signer's wheel is pulled from the banality of its quotidian state by being crippled of its usual function; the signification of the wheel is called into question, creating a tension of both meaning and movement.

Delicately perched, the wheel is absurd in its translucent stand. In monochrome, it creates a feeling of calm, yet something is awry. As the viewer sees the wheel begin to lean in its melting anchor point, glistening ice catches his eye. The shininess of the base and the growing accumulation of water along the edges of the ice block, stretching at a glacial yet visible rate along the surface from its source, announce the instability of the wheel's evertilting position. Along the wheel's edges the crevices slowly expand, the ice releasing its frozen grip on the tire's treads. The slowness with which this visualization of time occurs gives the viewer time to consider the duality of these states of flux: on the one hand, the icy

\footnotetext{
33 Ibid.

34 Signer traces his artistic influences back to minimalism and arte povera. While he was a sculpture student at the School of Applied Arts in Lucerne, Switzerland, he saw Harald Szeemann's exhibition "Live in Your Head: When Attitudes Become Form" in 1969 at the Kunsthalle Bern. He calls himself "a child of those times," while still distancing his own artistic practices from these precedents, saying: "I have always tried to find my own way, which cannot be quite straight. It is hard." Signer was particularly influenced by Robert Morris, whose work he found "open-minded" and useful as "tools for thought processes," exemplifying Signer's fascination with openness and a challenged concept of sculpture. Paula van den Bosch, "Paula van den Bosch in conversation with Roman Signer," in Roman Signer, ed. Gerhard Mack, Paula van den Bosch, and Jeremy Millar (London: Phaidon Press, 2006), 39 and 13.

35 Lutz Tittel, "A Conversation with Lutz Tittel (extract), 1984," in Roman Signer, ed. Gerhard Mack, Paula van den Bosch, and Jeremy Millar (London: Phaidon Press, 2006), 120.

36 This work is described as seen at the Walker Art Center's exhibition "The Quick and the Dead," April 25, 2009 - September 27, 2009.
} 


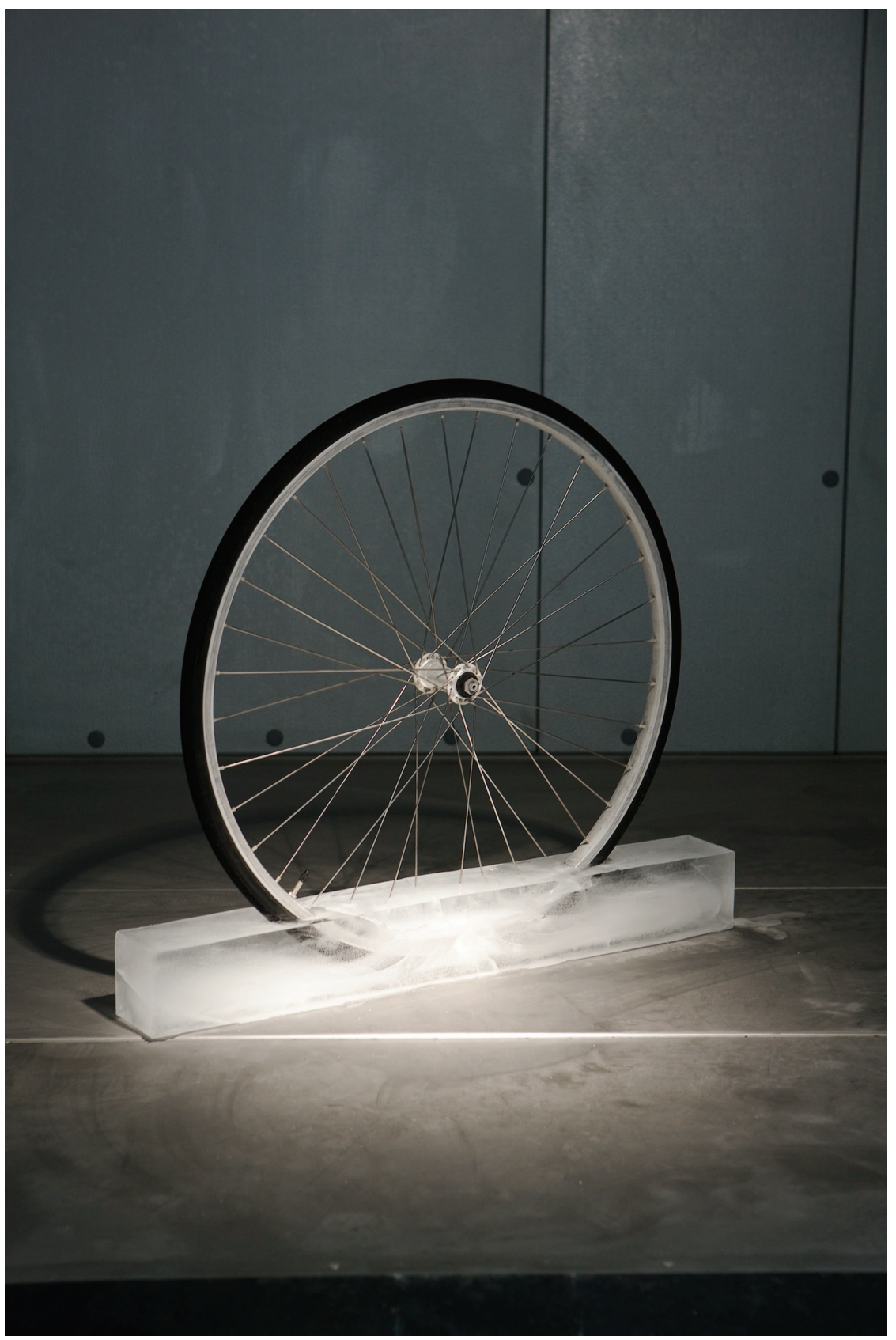

Figure 6

Roman Signer, Rad (Wheel), (1996/2008). Refrigerator cell, bicycle wheel, ice. Dimensions variable: ice block $10 \mathrm{~cm} \times 10 \times 80 \mathrm{~cm}$. Installation: Rochester Art Center, 2008. Photo: Gene Pitman. Courtesy of the artist and Hauser \& Wirth. 
base's transformation from frosty sturdiness to a trickling pool of water, and on the other hand, the wheel's transformation from rigid uselessness to tragic fall. In this transition across all states, Signer denies the wheel the productive movement it normally affords. In so doing, the viewer senses the parallel tension between the transitory states of movement of both the ice and the wheel, thus experiencing a continuous sense of anxiety through the absurdity of it all, until the wheel suddenly falls.

The variability and unpredictability of the interval of waiting are especially significant in Signer's work, which promises a cathartic moment or a highly-sensory, abrupt change of state. This foregrounds the importance of the viewer's active participation, for "the brilliance of the piece is how quickly you intuit what is waiting to eventually happen." ${ }^{37}$ Indeed, Signer acknowledges the fundamental importance of the interval of time the work takes up, the time during which both artist and viewer wait.

Somewhere there's an explosive charge, and the fuse is burning, and then you wait. The waiting is terrible. Terrible.... And you wait and wait, [imitates the noise of an explosion] and then you really feel as if you could fly, you are so completely free. It is an addiction. Perhaps this is my drug. ${ }^{38}$

Bound to the work itself, this temporal element marks a duration in which the beholder anticipates a significant change: a sort of catharsis, a freedom from the anxiety of waiting.

Time sculpture forces our attention by challenging our understanding of the status quo in the museum space - cannons shooting red wax into the corner, dough seeping slowly, tires going nowhere fast, and blocks of ice melting - jarring us from our own comfortable interaction with time. It grabs our attention; anxiously we wait on time sculpture's terms. The amount of time we spend in the museum runs parallel to the exertion of the work itself. How much are we willing to exert ourselves; how long will we pay attention? How deeply will time sculpture engage us?

\section{Bracketing Time: Beginnings and Ends of Perception}

Though we think we understand it, time is fundamentally inconceivable. Time is comprehensible only in intervals, and time sculpture provides one such interval. The time in which the work is still changing - "in production" or "in flux" - and the duration of the beholder's engagement with that time sculpture are inverted from the "usual" situation in which the viewer's experience is presumably endless, as in the "literalist" work which concerned Fried. It is precisely this endlessness of experience which distinguishes time sculpture from other sculpture. It changes the way we regard the viewer's perception of the work because the viewer's experience no longer seems endless: due to its climactic moment(s), it now has a duration. Can time sculpture, then, effectively bracket time?

The anticipation of the dynamism and catharsis intrinsic to time sculpture glues us to the spot and makes our experience a finite one during which we experience the anxieties and discomforts described above in the works of Kapoor, Whitelaw, Sailstorfer, and Signer. And it is a dynamic dimension that will occur again at (ir)regular intervals: tomorrow, twenty minutes from now, or in the next exhibition. As we have seen, these durations can be of varying lengths, even layered upon each other, such as the singular yet continual and minimal build-up of rubber under Zeit ist keine Autobahn, or the distinct yet multiple

\footnotetext{
37 Peter Eleey, curator of "The Quick and the Dead," at the Walker Art Center, Minneapolis, e-mail message to author, August 30, 2010.

38 Whitelaw, e-mail message to author, August 29, 2010.
} 
durations of the falling dough in Whitelaw's work. These durations can also be of varying levels of recognizability; they can be conceptual, in which case we know something will happen in our space yet no visible dynamism alludes to it, as in Signer's wheel, or they can be physical, in which case a steady movement indicates that we should wait, as in Kapoor's Svayambh. Yet across the works the collision of human time and object time induces a timebased anxiety and anticipation of waiting. How is our perception affected in this situation of duration which is so different from the endlessness Fried describes?

This anxiety-laden duration in front of the work of art, then, is key to our understanding of perception. French philosopher Henri Bergson developed the idea of duration as a way to counter philosophical arguments of his day that posited memory as a kind of matter, which he saw as a reduction in the idea of man's free will and spirituality. ${ }^{39}$ Though over a hundred years old, his fundamental understanding of time is highly relevant to our reading of time sculpture because of his notion that it is within a certain duration - between the awareness of stimulation and the reaction to it - that the pivotal moment of mental activity lies. A central concept for Bergson was that within this temporal space or duration there "is no perception which is not full of memories. With the immediate and present data of our senses we mingle a thousand details out of our past experience." 40 Our experience, then, is always tainted by memory, a condition we cannot escape. For the duration of our experience with time sculpture, our memories color our thought processes in front of the work of art, making our perception, in Bergson's view, one of individuality and higher order.

To further explain this position, Bergson posited two states of being: first, a vital order, which is intuitive (willed, creative, individual; it continues fluidly uniting each moment of experience indefinitely through an intuited succession, not a juxtaposition), and secondly a geometrical order, which is intellectual (automatic, non-directional; it neglects natural unity and breaks the world into homogenous, artificial units). We are, he says, usually in this latter state of intellect, operating on autopilot; this is a condition which exists in space and does not engage higher orders of thinking and is not an ideal or desirable state of being. Rather, Bergson prefers the vital order, which exists in time and in which we are alert, engaged, and synthesizing our memories with sensory input in real time. Intuition necessarily delays the automatic reaction characteristic of the geometric state. In fact, Bergson rejected the concept of time as having spatial qualities, because this denied its durational capacity. Instead, he saw time as having a one-directional forward momentum, pointing out that we cannot go backward in it in the same way that we can revisit a location, because - unlike temporal elements - all spatial elements are alike and can be reordered. These principles of geometrical order can be predicted because they are based on patterns and universal laws. Thus, space and time begin to illuminate the binary structure of Bergson's theory.

What is easy to see is that in practice we cannot always be in a state of intellect (automatic thinking) nor can we always be in a state of intuition (active thinking). What is less clear is how, based on Bergson's system of dichotomies, all matter must fall into either the geometrical or vital category. There is a problem here, for art cannot exist wholly within either the geometric or vital realms. ${ }^{41}$ Art is not totally vital because art itself exists, at least partly, within this geometrical order as a non-continuous entity, made of discrete forms or shapes and of discernable, finite durations (the tempo of a musical score, the content inside the frame of a painting, the time until catharsis of a time sculpture). These elements are

\footnotetext{
39 For more on Bergson's concept of duration, on which he wrote extensively, see for example Time and Free Will: An Essay on the Immediate Data of Consciousness (1889) and Matter and Memory (1896).

40 Henri Bergson, Matter and Memory (1896), trans. Nancy Margaret Paul and W. Scott Palmer (Mineola, New York: Dover Publications, Inc., 2004), 24.

41 For a nuanced analysis of the work of art in relation to Bergson's theories, see Ruth Lorand, "Bergson's Concept of Art," The British Journal of Aesthetics 39, no. 4 (October 1999), 400-415.
} 
conceptually and fundamentally irreconcilable for Bergson with the faculties of the vital order or intuitive state. Likewise, art cannot be totally geometrical because there are no independent principles that govern it, and because Bergson sees geometrical aspects of the world to be ordered, and therefore predictable. ${ }^{42}$ But we know art to be unpredictable, and Bergson agrees, for he sees no distinction between the moment of artistic conception and creation. These are inseparable and occupy the same instant because art is a "truly new form," a form which could not know its meaning, content, or appearance before the very moment of its consummation: an unpredictable, and thus intuitive, order. ${ }^{43}$ Art, then, is predictable neither for the artist nor for the beholder, for if it was, it would not be unique. Furthermore, it relies upon its surroundings for its interpretation, constituting not only the fabrication of a singular work of art, but also a singular experience for the beholder.

In this way, then, art escapes being always in either the geometric or the vital realm, because, as we can see, certain of its characteristics or components exist in both orders. We are therefore able to argue that art exists in the geometrical realm, resting on discrete and concrete compositional elements and in a set duration at the same time that it necessitates the vital orders of its maker's intuitive creation and its beholders' continual perception. Bergson's philosophy is based on polarities that leave no room for an interaction between these two states, but in fact require cooperation. The duration of time sculpture is more precisely defined than that of its artistic counterparts, painting and static sculpture. Since we cannot always be in a state of attentive concentration or absorption as Bergson desired, time sculpture presents a very fitting case in which we recognize the distinction between these two states. Under these circumstances, we must analyze the artwork intuitively, for analysis by intellect would produce a list of non-ordered facts.

It is precisely because art falls between Bergson's categories that we are offered a sort of portal into the transitory states of our own condition as observers. Time sculpture is unique in relation to art generally, because, as I argue in this paper, it triggers Bergson's vital state since it defines an explicit experiential duration. Because time sculpture defies definition in terms of Bergson's dichotomy, its instability induces a shift in the viewer's perception while in front of the work. The anxious moment in which we realize we are waiting - our realization of the collision of object time and human time - snaps us from our quotidian or automatic condition, throwing us into a heightened awareness that necessitates our operation within the intuitive and attentive state. Indeed, what makes time sculpture so powerful is that it defines the duration of this intuitive state, and in so doing it is as if the beholder is operating on the object's time, not human time - stuck in the moment, in a rush of memory and image.

\footnotetext{
42 Yet by this estimation, art would also continue forever, for as part of the vital realm, it would depend upon "what may be called an endless multiplicity of contracting into a duration too narrow to permit of the separation of its moments." Bergson, Matter and Memory, 271-272.

43 As Lorand notes, "There is no basis for prediction in the case of art or in any case of a 'truly new form.' Art expresses an unpredictable order." Lorand, "Bergson's Concept of Art," 405.
} 


\section{(cc) EY-NC-ND}

This work is licensed under a Creative Commons Attribution-Noncommercial-No Derivative Works 3.0 United States License.

\section{ULIS D-Sorke}

This journal is operated by the University Library System of the University of Pittsburgh as part of its D-Scribe Digital Publishing Program, and is co-sponsored by the University of Pittsburgh Press. 